\title{
Evaluation of risk malignancy index in the pre-operative diagnosis of benign and malignant ovarian neoplasms
}

\author{
Niroopama Pushpagiri ${ }^{1}$, Saranya Nagalingam ${ }^{2 *}$
}

\begin{abstract}
${ }^{1}$ Department of Obstetrics and Gynecology, Narayana Medical College and Hospital, Chinthareddypalem, Nellore, Andhra Pradesh, India

${ }^{2}$ Department of Intensive Care, Velammal Medical College, Hospital and Research Institute, Madurai, Tamil Nadu, India
\end{abstract}

Received: 12 May 2018

Accepted: 23 June 2018

\section{*Correspondence:}

Dr. Saranya Nagalingam,

E-mail: dr.n.saranya@gmail.com

Copyright: ( ) the author(s), publisher and licensee Medip Academy. This is an open-access article distributed under the terms of the Creative Commons Attribution Non-Commercial License, which permits unrestricted non-commercial use, distribution, and reproduction in any medium, provided the original work is properly cited.

\begin{abstract}
Background: Preoperative discrimination between benign and malignant ovarian neoplasm is necessary to optimally plan for an appropriate surgical treatment. Women with malignant ovarian tumours should be referred to a gynaecologic oncologist for the quality of cytoreductive surgery leading to increased survival. The aim of this study is to determine the role of Risk of Malignancy Index (RMI) incorporating menopausal status, serum CA 125 levels and ultrasound features in discriminating benign from malignant ovarian neoplasms.

Methods: A prospective cohort study was conducted for 2 years among 110 women with ovarian neoplasms referred to Narayana Medical College and Hospital, Nellore a tertiary care centre for diagnosis and management. The sensitivity, specificity, positive and negative predictive values of menopausal status, ultrasound finding of ovarian neoplasms, levels of serum CA-125 separately and combined into the RMI were calculated and compared. $(\mathrm{RMI}=\mathrm{U}$ X M X Serum CA- 125). Women of all ages admitted with ovarian masses in Narayana Medical College, Nellore. Women whose histopathology report turned out to be non-neoplastic ovarian tumours or other adnexal masses.

Results: RMI $>250$ had a sensitivity of $70.8 \%$ (95\%CI 54.4-87.2), a specificity of $87 \%$ (95\%CI 76.5-97.7), a positive predictive value of $81 \%$ and negative predictive value of $79.4 \%$ for the diagnosis of malignant neoplasms.

Conclusions: The risk of malignancy index is a simple scoring system and easily applicable and effective method for evaluating a patient in discriminating benign and malignant ovarian neoplasms efficiently to optimize therapy. It facilitates timely referral to gynecological oncology unit for adequate staging and optimal debulking.
\end{abstract}

Keywords: Menopausal status, Ovarian neoplasm, Risk of Malignancy Index, Serum levels of CA-125, Ultrasound score

\section{INTRODUCTION}

Ovarian cancer is an important cause of cancer deaths from gynecological malignancy globally with peak incidence of 56 to 60 years of age and are often asymptomatic in early stage resulting in diagnostic delay with 5 -year survival as low as $10 \%$. This study mainly emphasizes that early detection using standardized method for preoperative identification of malignant neoplasms and timely referral to a gynecologic oncologist has been proven to increase survival in patients with ovarian cancer. ${ }^{1}$ The results of various studies done on RMI show that the benign-malignant determination of ovarian tumors could be managed with higher sensitivity and specificity using RMI. The main advantage of this method compared with other approaches such as color doppler ultrasonography or the use of different tumor 
markers, is that RMI can be used easily in lessspecialized units. ${ }^{2,3}$

\section{METHODS}

A prospective study was conducted on 110 women in a tertiary care hospital with ovarian tumors who were admitted for surgical management. Detailed history was obtained followed by general and gynaecological examination. Pre-operative evaluation was done by pelvic ultrasound and serum samples were collected for tumour marker analysis. Ultrasound findings, serum levels of CA-125 and menopausal status were noted.

\section{Inclusion criteria}

- Women of all ages admitted with ovarian masses in Narayana Medical College, Nellore.

\section{Exclusion criteria}

- Women whose histopathology report turned out to be non-neoplastic ovarian tumours or other adnexal masses.

Serum CA 125 levels was determined by radioimmune assay. Serum levels of $35 \mathrm{U} / \mathrm{ml}$ were taken as cut off and the levels above it were considered as abnormal.

\section{Ultrasound scoring}

In all studied cases, ultrasound was performed using 3.75 $\mathrm{MHz}$ abdominal transducer or $7.5 \mathrm{MHz}$ vaginal probe transducer. Ultrasound findings were scored with one point for each of the following: multilocular cyst, evidence of solid areas, bilateral lesions, presence of ascites and intra-abdominal metastases. Ultrasound score was assigned as $0(U=0)$ if they do not satisfy the above mentioned criteria, $U=1$ if one criteria was fulfilled, $U=3$ if 2 or more criteria were fulfilled.

\section{Menopausal status}

Pre-menopausal age group was scored as 1 and postmenopausal as 3. Women were considered as postmenopausal if they were amenorrheic for more than a year not associated with any other conditions or if they were at least 50 years old and had undergone a prior hysterectomy.

RMI score was calculated as,

RMI score=Ultrasound score (U) $\mathrm{x}$ Menopausal status (M) x serumCA-125 (C)

Imaging modalities like CT and or MRI were performed in ovarian neoplasms suspecting malignancy. All the specimens were sent for histopathological examination. Borderline ovarian tumors were classified as malignant ovarian neoplasms. Non-ovarian adnexal masses and non- neoplastic ovarian masses were excluded from the study. RMI was correlated with surgical findings and final histopathology report.

\section{Statistical analysis}

Data were entered in an excel sheet and statistical analysis was performed. Chi square test was used to compare the demographic, biochemical and ultrasonographic data of subjects with benign and malignant ovarian masses. The sensitivity, specificity, negative and positive predictive values of RMI were calculated.

For all statistical comparisons, a level of $\mathrm{p}<0.05$ was accepted as being statistically significant.

\section{RESULTS}

A total of 110 women with ovarian neoplasms were studied of which $62(56 \%)$ were benign and $48(44 \%)$ were malignant. The mean age of the study population with benign neoplasms was 41 years with the mean CA 125 levels and RMI score being 24 and 55 respectively; the corresponding values in the subjects with malignant neoplasms were 47 years, 51 and 253 respectively. Age wise distribution of benign and malignant ovarian neoplasms was shown in Figure 1. 81\% of ovarian tumors in age group $<55$ years were benign, while $72 \%$ of the ovarian tumors in age group $>45$ years were found to be malignant. $63 \%$ of ovarian tumours were benign in premenopausal age group where as $60 \%$ of the ovarian tumours in post-menopausal age group were found to be malignant. The distribution of study participants by age, menopausal status, serum CA 125 levels and USG score were shown in the Table 1.

Table 1: Distribution of subjects by age, menopausal status, USG score and serum CA 125 levels in women with benign and malignant ovarian neoplasms.

\begin{tabular}{|llll|}
\hline Variables & $\begin{array}{l}\text { Benign } \\
\mathbf{N}=62\end{array}$ & $\begin{array}{l}\text { Malignant } \\
\mathbf{N}=48\end{array}$ & P value \\
\hline Age & & & \\
\hline$<30$ & $13(21 \%)$ & $4(8 \%)$ & 0.099 \\
\hline 30 to 44 & $20(32 \%)$ & $10(20 \%)$ & \\
\hline 45 to 54 & $17(28 \%)$ & $21(44 \%)$ & \\
\hline$>55$ & $12(19 \%)$ & $13(28 \%)$ & \\
\hline $\begin{array}{l}\text { Menopausal status } \\
\text { Pre-menopausal }\end{array}$ & $39(63 \%)$ & $19(40 \%)$ & 0.025 \\
\hline $\begin{array}{l}\text { Menopause } \\
\text { USG score }\end{array}$ & $23(37 \%)$ & $29(60 \%)$ & \\
\hline 0 & $19(30 \%)$ & $3(6 \%)$ & $<0.0001$ \\
\hline 1 & $29(47 \%)$ & $13(27 \%)$ & \\
\hline 3 & $14(23 \%)$ & $32(67 \%)$ & \\
\hline CA 125 & & & \\
\hline$<35$ & $45(73 \%)$ & $17(36 \%)$ & $<0.0001$ \\
\hline$>35$ & $17(27 \%)$ & $31(64 \%)$ & \\
\hline
\end{tabular}


Menopausal status, USG score and CA 125 levels were statistically significant with the $\mathrm{p}$ values of $0.025,0.0001$ and 0.0001 respectively. Chi square test was done to find out the association between these variables.

\section{Predictive values}

RMI > 250 had a sensitivity of $70.8 \%$ (54.4-87.2), a specificity of $87 \%$ (76.5-97.7), positive predictive value (PPV) of $81 \%$ and negative predictive value (NPV) of $79.4 \%$ in detecting malignant neoplasms. RMI had poor sensitivity in detecting non-epithelial malignant ovarian neoplasms. Regarding ultrasound parameters, multilocations was found in both benign as well as malignant ovarian neoplasms. Presence of ascites and solid areas were found mostly in malignant tumours. Among the malignant tumors, $67 \%$ of them had USG score 3 . The USG score had sensitivity $66.4 \%$, specificity $77.4 \%$, PPV $31 \% \%$ and NPV of $32.4 \%$ in detecting malignant tumours. With regard to the menopausal status, it had sensitivity of $60.4 \%$, specificity $63 \%$, PPV $55.7 \%$, NPV of $67.2 \%$. In present study, Serum CA 125 levels has the sensitivity of $64.6 \%$, specificity $72.6 \%$, positive predictive value $64.6 \%$, negative predictive value of $72.6 \%$ in determining malignant ovarian neoplasms and it was found to be elevated in most of the epithelial ovarian carcinomas (Table 2).

Table 2: Predictive values of RMI, Menopausal status, serum CA 125, and USG score of malignant and benign adnexal masses.

\begin{tabular}{|c|c|c|c|c|c|c|}
\hline Variables & $\begin{array}{l}\text { Malignant } \\
(\mathbf{N}=\mathbf{4 8})\end{array}$ & $\begin{array}{l}\text { Benign } \\
(\mathrm{N}=62)\end{array}$ & $\begin{array}{l}\text { Sensitivity } \\
\text { CI }\end{array}$ & $\begin{array}{l}\text { Specificity } \\
\text { CI }\end{array}$ & $\begin{array}{l}\text { PPV } \\
\text { CI }\end{array}$ & $\begin{array}{l}\text { NPV } \\
\text { CI }\end{array}$ \\
\hline \multicolumn{7}{|l|}{ RMI } \\
\hline$>250$ & $34(71 \%)$ & $8(13 \%)$ & $70.8 \%$ & $87 \%$ & $81 \%$ & $79.4 \%$ \\
\hline$<250$ & $14(29 \%)$ & $54(87 \%)$ & $(54.4-87.2)$ & $(76.5-97.7)$ & $(66-91)$ & $(67.2-91.7)$ \\
\hline \multicolumn{7}{|c|}{ Menopausal status } \\
\hline Menopause & $29(60 \%)$ & $23(37 \%)$ & $60.4 \%$ & $63 \%$ & $55.7 \%$ & 67.2 \\
\hline Pre-menopausal & $19(40 \%)$ & $39(63 \%)$ & $(43-78)$ & $(47.6-78.2)$ & $(38.6-73)$ & $(51.8-82.6)$ \\
\hline \multicolumn{7}{|l|}{ USG score } \\
\hline 3 & $32(67 \%)$ & $14(23 \%)$ & $66.6 \%$ & $77.4 \%$ & $70 \%$ & $75 \%$ \\
\hline 0,1 & $16(33 \%)$ & $48(77 \%)$ & $(49.7-83.7)$ & $(64-90.7)$ & $(52.6-82.5)$ & $(61.5-86.5)$ \\
\hline \multicolumn{7}{|l|}{ CA 125} \\
\hline$>35$ & $31(64 \%)$ & $17(27 \%)$ & $64.6 \%$ & $72.6 \%$ & $64.6 \%$ & $72.6 \%$ \\
\hline$<35$ & $17(36 \%)$ & $45(73 \%)$ & $(47.3-81.8)$ & $(58.4-86.7)$ & $(47.3-81.8)$ & $(58.4-86.7)$ \\
\hline
\end{tabular}

Table 3: Descriptive statistics of age, serum CA 125 levels and RMI score - Benign ovarian neoplasms.

\begin{tabular}{|lllllll|} 
& N & Min & Max & Mean & Median & $\begin{array}{l}\text { Std. } \\
\text { Dev }\end{array}$ \\
Age & 62 & 19 & 64 & 41.74 & 42.5 & 11.42 \\
\hline CA-125 & 62 & 2 & 87 & 24.24 & 16 & 21.15 \\
RMI & 62 & 0 & 333 & 55.12 & 15 & 89.90 \\
\hline
\end{tabular}

Table 4: Descriptive statistics of age, serum CA 125 levels and RMI score - Malignant ovarian neoplasms.

\begin{tabular}{|lllllll|} 
& N & Min & Max & Mean & Median & $\begin{array}{l}\text { Std. } \\
\text { Dev }\end{array}$ \\
\hline Age & 48 & 23 & 68 & 47.5 & 48 & 9.98 \\
\hline CA-125 & 48 & 9 & 114 & 51.22 & 39 & 30.23 \\
\hline RMI & 48 & 0 & 972 & 253.84 & 264.7 & 182.44 \\
\hline
\end{tabular}

Table 5: Distribution of subjects by RMI scoring.

\begin{tabular}{|lll|}
\hline RMI & Benign $(\mathrm{N}=62)$ & Malignant $(\mathrm{N}=48)$ \\
\hline$<25$ & $38(61 \%)$ & $5(10 \%)$ \\
\hline $25-250$ & $16(26 \%)$ & $9(19 \%)$ \\
\hline$>250$ & $8(13 \%)$ & $34(71 \%)$ \\
\hline
\end{tabular}

\section{Histo-pathological examination results}

Epithelial ovarian tumors constituted the majority in both benign as well as malignant group. Borderline tumours constituted $6.3 \%$ of all the total cases. Malignancy rate increased with the age.

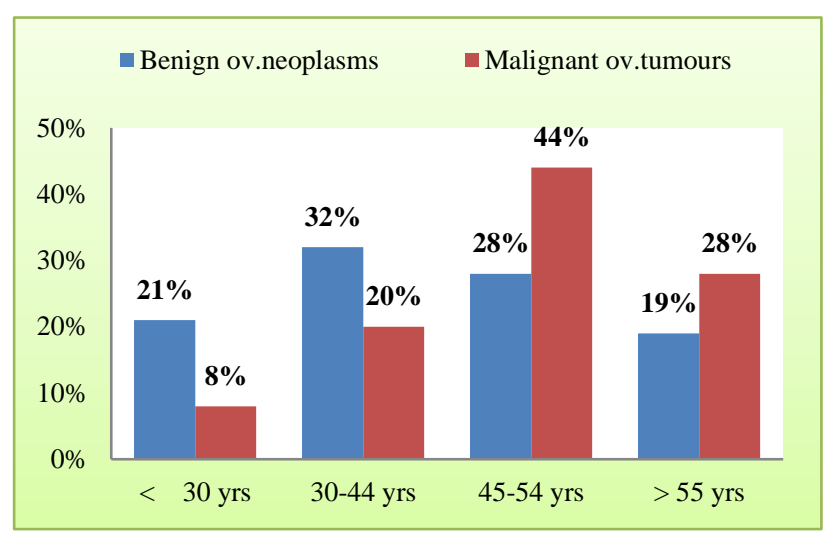

Figure 1: Age wise distribution of benign and malignant ovarian neoplasm. 
Out of 62 benign lesions, 36 (58\%) were serous cystadenoma followed by mucinous cystadenoma 11 (18\%), mature cystic teratoma $9(14 \%)$, adenofibroma 2 (3\%), fibroma $2(3 \%)$, brenner's tumour $1(2 \%)$ and gynandroblastoma 1 (2\%) (Figure 2).

Similarly of overall 48 malignant lesions, serous cystadenocarcinoma constituted 19 (40\%) followed by mucinous cystadenocarcinoma, borderline serous and mucinous cystadenoma. Endometroid carcinoma formed $7(15 \%)$ of the malignant lesions. (Figure 3).

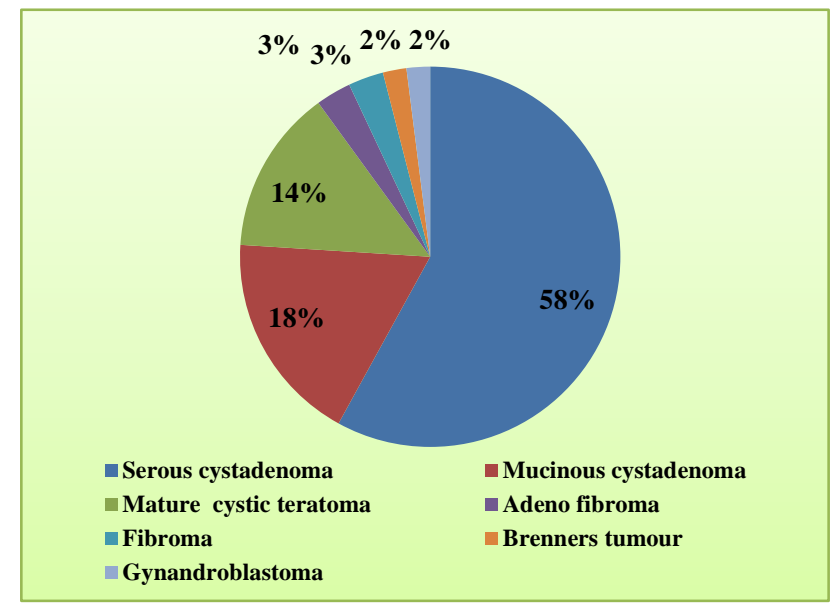

Figure 2: Histopathological pattern of Benign ovarian neoplasms.

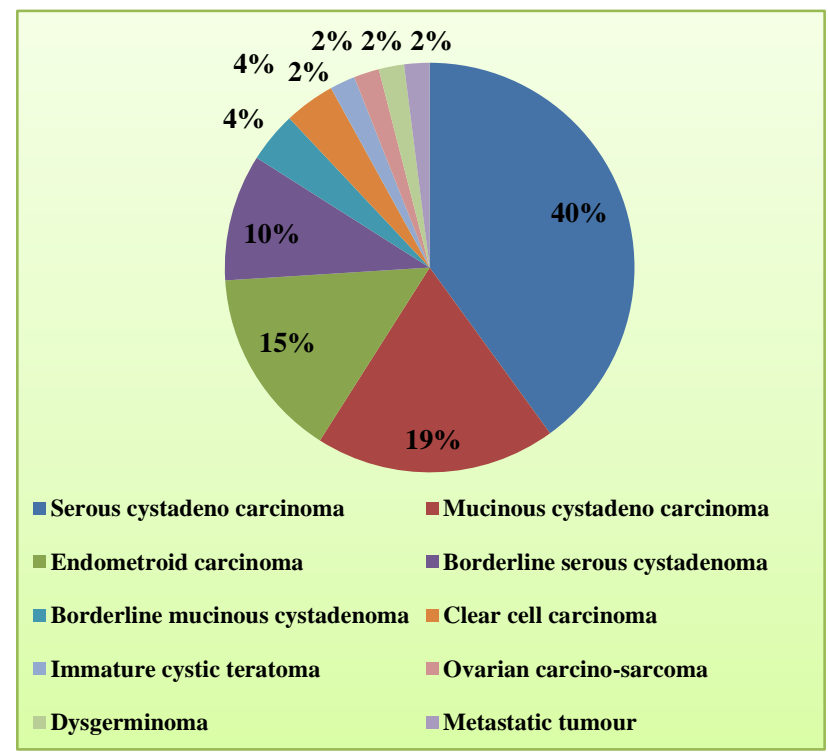

Figure 3: Histopathological pattern of Malignant ovarian neoplasms.

\section{DISCUSSION}

The estimation of malignancy risk in patients with ovarian tumors is important to improve survival of patients with early ovarian cancer, as reported in several studies. $^{4-6}$ The most effective diagnostic tool should be accurate, easy to perform, and cheap. Furthermore, it should be helpful to prioritize treatment for high risk patients and in deciding the extent and time of surgery for low risk patients.

Jacobs et al originated the concept of the Risk of Malignancy Index (RMI) in 1990 combining serum levels of CA-125, ultrasound score, and menopausal status into the assessment of a patient with an adnexal mass, and it is known as RMI 1. They found that the RMI 1 had a sensitivity of $85.4 \%$ and a specificity of $96.9 \%$ when using a cut-off level of 200 to indicate malignancy. ${ }^{7}$

The aim of this prospective cohort study was to evaluate the role of RMI 1 in distinguishing benign from malignant adnexal masses. The sensitivity and specificity of the parameters used for calculating RMI were calculated individually and compared with the RMI. It was found that sensitivity and specificity of menopausal status, ultrasound scoring and serum CA-125 levels when calculated individually were low compared to RMI scoring system when cut off was taken as 250. RMI translates the morphological description of the pelvic mass into objective numerical data, reducing the bias attributable to the examiner's subjectivity and was found to be more in detecting malignant neoplasms. It was also observed in our study that RMI has poor sensitivity in detecting borderline ovarian tumours and non-epithelial ovarian neoplasms.

According to RCOG guidelines, triaging women using the risk of malignancy index shows: ${ }^{8}$

- A - Low risk - RMI $<25$, risk of cancer $<3 \%$

- B- Moderate risk - RMI 25-250, risk of cancer 38.2\%

- C-High risk - RMI $>250$, risk of cancer $91.2 \%$

Using a cutoff point of 250 , a sensitivity of $70 \%$ and specificity of $90 \%$ was achieved.

Engelen et al, study on 302 women with adnexal mass indicated an RMI at a cutoff point of 250 had a sensitivity of $88.2 \%$, a specificity of $74.3 \%$, a PPV of $71.3 \%$, a NPV of $90 \%$ for diagnosing invasive lesions. ${ }^{9}$

Yavuzcan A et al, evaluated 153 patients with adnexal masses and found that the cut-off value of 250 for RMI-1 provided $95.9 \%$ inter-observer agreement, yielding $75.0 \%$ sensitivity, $95.9 \%$ specificity, $93.5 \% \mathrm{NPV}$ and $82.8 \%$ PPV. ${ }^{10}$ Similarly, a study conducted by Ozbay et al on 119 patients in 2015 found that the best performance cut-off value for RMI 1 in differential diagnosis of adnexal masses was 250; with this cut-off value, the specificity has risen from $93.1 \%$ to $93.8 \%$ while histopathologic correlation has risen from $85.8 \%$ to $85.9 \%$, and sensitivity of $60.9 \%$, PPV of $75.7 \%$, NPV of $88.3 \%$, total correlation of $85.9 \%$ was observed. Their study showed that RMI 1 has a significant (A.U.C: 0.87 (0.81-0.94); $\mathrm{p}<0.001)$ predictive power in differentiation of benign and malignant patients. ${ }^{11}$ In present study, 
using the same cut off point 250 , a sensitivity of $70.8 \%$, specificity of $87 \%$, PPV of $81 \%$ and NPV of $79.8 \%$ was achieved. According to RCOG guidelines, for tumors classified as low risk, the proposed management is laparoscopic surgery in a gynecology unit. If at moderate risk, laparoscopic surgery in a cancer unit and if malignancy is suspected, full staging procedure is advised. If at high risk, full staging procedure in a cancer centre is advised.

In present study among 110 patients, for suspected malignant tumors exploratory staging laparotomy was performed with the help of surgical oncologist and post operatively chemotherapy was started for tumors diagnosed to be malignant by histopathology and followed up.

\section{CONCLUSION}

The risk of malignancy index is a simple scoring system which can be used in less specialized gynecology centers. RMI-1 is a non-invasive, easily accessible, applicable, inexpensive and beneficial method with significant predictability in differentiating benign and malignant ovarian neoplasms preoperatively, thus can effectively be used in clinical practice and was useful for referring high risk patients to tertiary care centers at an early stage.

\section{Funding: No funding sources}

Conflict of interest: None declared

Ethical approval: The study was approved by the Institutional Ethics Committee

\section{REFERENCES}

1. Gillis CR, Hole DJ, Still RM, Davis J, Kaye SB. Medical audit, cancer registration, and survival in ovarian cancer. Lancet. 1991;337:611-2.

2. Bourne T, Campell S, Steer C, Whitehead MI, Collins WP. Transvaginal colour flow imaging: a possible new screening technique for ovarian cancer. Br Med J. 1989; 299:1367-70.

3. Jacobs IJ, Rivera H, Oram DH, Bast RC. Differential diagnosis of ovarian cancer with tumour markers CA 125, CA 15-3 and TAG 72.3. BJOG: Int J Obstetr Gynaecol. 1993;100(12):1120-4.

4. Earle CC, Schrag D, Neville BA, Yabroff KR, Topor M, Fahey A, et al. Effect of surgeon specialty on processes of care and outcomes for ovarian cancer patients. J National Cancer Inst. 2006;98(3):172-80.

5. Engelen MJ, Kos HE, Willemse PH, Aalders JG, de Vries EG, Schaapveld M, et al. Surgery by consultant gynecologic oncologists improves survival in patients with ovarian carcinoma. Cancer: Interdisciplinary Int $\mathbf{J}$ Am Cancer Soc. 2006;106(3):589-98.

6. Gillis C, Hole D, Still RM, Davis J, Kaye SB. Medical audit, cancer registration, and survival in ovarian cancer. Lancet. 1991;337(8741):611-2.
7. Jacobs I, Oram D, Fairbanks J, Turner J, Frost C, Grudzinskas JG. A risk of malignancy index incorporating CA-125, ultrasound and menopausal status for the accurate preoperative diagnosis of ovarian cancer. Br J obstet Gynaecol. 1990;97:922-9.

8. Rufford BD, Jacobs IJ. Green-top Guideline No. 34. Ovarian cysts in postmenopausal women. London, UK: Royal College of Obstetricians and Gynaecologists, 2003. Available at http://www.rcog.org.uk/ files/rcogcorp/GTG3411022011.pdf

9. Engelen MJA, Bongaerts AHH, Sluiter WJ, de Haan $\mathrm{HH}$, Bogchelman DH, TenVergert EM, et al. Distinguishing benign and malignant pelvic masses: The value of different diagnostic methods in everyday clinical practice. Eur J Obstetr Gynecol Reprod Biol 2008;136(1):94-101.

10. Yavuzcan A, Caglar M, Ozgu E, Ustun Y, Dilbaz S, Ozdemir I, Yildiz E, et al. Should cut-off values of the risk of malignancy index be changed for evaluation of adnexal masses in Asian and Pacific populations? Asian Pac J Cancer Prev. 2013;14(9):5455-9

11. Ozbay PO, Ekinci T, Çaltekin MD, Yilmaz HT, Temur $\mathrm{M}$, Yilmaz O, et al. Comparative evaluation of the risk of malignancy index scoring systems (1-4) used in differential diagnosis of adnexal masses. Asian Pacific $\mathbf{J}$ Cancer Preven. 2015;16(1):345-9.

12. Hecher $K$, Campbell S, Doyle $P$, Harrington $K$, Nicoladies K. Asessment of fetal compromise by Doppler ultrasound investigation of the fetal circulation. Circulation. 1995;91:129-38.

13. Baschat AA, Gembruch U, Weiner CP, Harman CR. Qualitative venous Doppler waveforms analysis improves prediction of critical perinatal outcome in premature growth restricted foetuses. Ultrasound Obstet Gynacol. 2003;22:240-5.

14. Brown MA, Lindheimer MD, Swiet M, Assche VA, Moutquin JM. The classification and diagnosis of the hypertensive disorders of pregnancy: statement from the international society for the study of hypertension in pregnancy (ISSHP). Hypertens Pregnancy. 2001;20:1924.

15. Kurmanavicius J, Florio I, Wisser J, Hebisch G, Zimmermann R, Muller $\mathrm{R}$ et al. Refence resistance indices of the umbilical, fetal middle cerebral and uterine arteries at 24-42 weeks of gestation. Ultrasound Obstet Gynecol. 1997;10:112-20.

16. Ozeren M, Dinc H, Ekmen U, Senekayli C, Aydemir V. Umbilical and middle cerebral artery Doppler indices in patients with preeclampsia. Eur J Obstet Gynecol Reprod Biol. 1999;82:11-6.

17. Yoon BH, Lee CM, Kim SW. An abnormal umbilical artery waveform: A strong and independent predictor of adverse perinatal outcome in patients with preeclampsia. Am J Obs Gyn. 1994;171:713-21.

Cite this article as: Pushpagiri N, Nagalingam S. Evaluation of risk malignancy index in the pre operative diagnosis of benign and malignant ovarian neoplasms. Int J Reprod Contracept Obstet Gynecol 2018;7:3126-30. 